\title{
Sedimentology and Paleogeographic Synthesis of Cretaceous Sediments in Auchi Area of Anambra Basin
}

\author{
ILEGIEUNO, OA; *IGHODARO, EJ; SUNNY, RO \\ Department of Geology and Petroleum Studies, Western Delta University, Oghara, Delta State, Nigeria. \\ *Corresponding author: Email: ehikacross@gmail.com, +2348038598495
}

\begin{abstract}
The sedimentary rock in the Auchi area of Edo State constitutes part of the Upper Cretaceous Deposits of the Anambra Basin, which has its depocentre in Eastern Nigeria. Lithostratigraphic and Sedimentological studies carried out on twenty eight (28) selected samples from a section of a road-cut show that the sediments range from fine through medium to coarse grained. Sorting is poor to moderate. Grain size analysis shows that the sediments are strongly fine skewed and they exhibit mesokurtic to platykurtic kurtosis. These coupled with the various colours observed in the sediment, ranging from whitish sand through yellowish brown, pink and reddish brown possibly indicate a non-marine environment and a fluviatile to deltaic environment of sedimentation is suggested. The sediments might have been transported in a fairly high energy medium and deposited under a slightly fluctuating velocity.
\end{abstract}

DOI: https://dx.doi.org/10.4314/jasem.v24i5.32

Copyright: Copyright (C) 2020 Ilegieuno et al. This is an open access article distributed under the Creative Commons Attribution License (CCL), which permits unrestricted use, distribution, and reproduction in any medium, provided the original work is properly cited.

Dates: Received: 10 March 2020; Revised: 29 April 2020; Accepted: 28 May 2020

Keywords: Sedimentology, Cretaceous, Paleogeography, Grain size, Anambra Basin

The sedimentary rock in Auchi area form parts of the Upper Cretaceous sediments of the Anambra Basin. The sedimentary rock in the basin, which continues into the West of the Niger, underlies a considerable stretch of country, covering the entire land area of Agenebode, Fugar, Okpekpe, Uzairue and Auchi further west. It is bounded to the north by the Crystalline Basement Complex of Nigeria (G. S. N. 1:100,000 series, Auchi sheet 266). Lithostratigraphic observation of a sedimentary rock section reveals that the rock unit which is about $20 \mathrm{~m}$ thick at the representative section consist dominantly of partially indurated sandstone with occasional occurrence of sandy - clay at intervals. The top of the unit is capped by reddish - brown sandy - clay at intervals. The top of the unit is capped by reddish - brown, sandy - clay intermixed with ferruginized sandstone and laterite soil.

\section{MATERIALS AND METHODS}

Study Area: The area under study is situated along Auchi - Igarra road in Etsako Local Government Area of Edo State. The area lies within latitude $6^{\circ} 10^{\prime} \mathrm{E}$ and $6^{0} 20^{\prime} \mathrm{E}$ and between longitude $7^{\circ} \mathrm{N}$ and $7^{0} 10^{\prime} \mathrm{N}$ respectively.

Cretaceous Stratigraphy and Paleogeography of Southern Nigeria: The Cretaceous sedimentary rocks of Auchi area form a part that have accumulated in a variety of facies and thicknesses. According to
Adeleye (1975), they cover about one-fourth of the land surface area of Nigeria. The depositional history started in the late Mesozoic time following the separation of the African and South - American continental landmass (Wright, 1975). Paleogeography reconstruction of the Cretaceous sequence has been attempted by several workers among whom are: Adegoke (1969, 1978); Reyment (1965), Murat (1972); Adeleye (1975) and the Peters (1972). Based on stratigraphic evidence, the general concensus among workers is that basement subsidence, accompanied by normal marine transgression began in West Africa during Albian times. Deposition in southern Nigeria was first restricted to the eastern half of the Mesozoic - Cenozoic coastal basins but later extended to other parts of Maastrichtian (Adegoke, 1969).

Field Observation and Sample Collection: The fieldwork was carried out to locate suitable outcrop sections and to determine the depth and thickness of the sections in the locality. Based on physical attributes such as colour, grain size and sorting, representative samples were taken from each distinct lithologic unit and were carefully described.

Sample Analysis: The laboratory analysis involved detailed analytical study of the samples collected in the field with a view to determine their geological characteristics. The laboratory work include: Grain size analysis of sand size particles.

*Corresponding author: Email: ehikacross@gmail.com, +2348038598495 


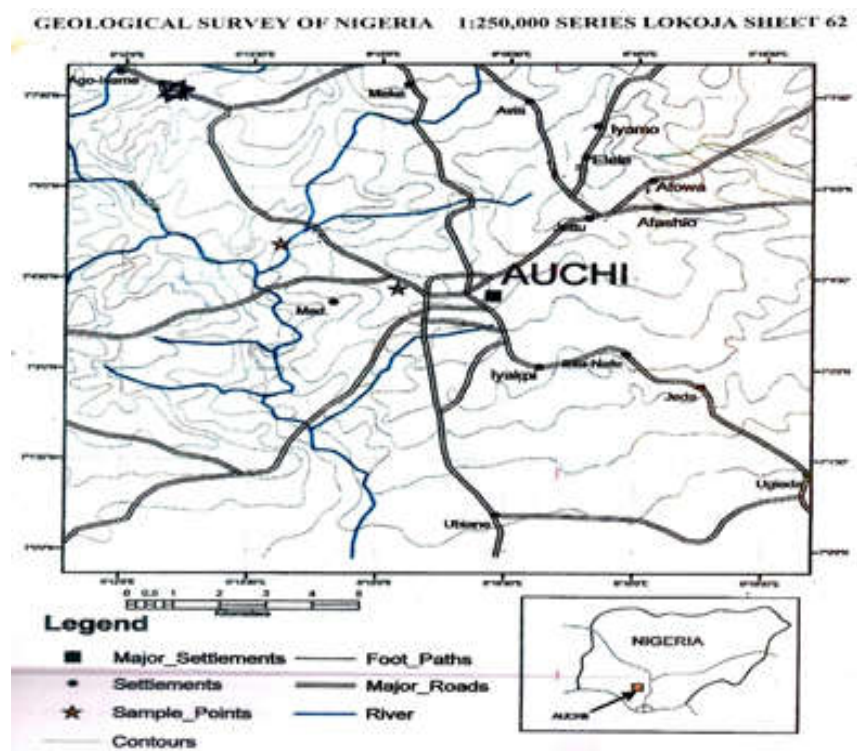

Fig. 1: Map of Auchi and environs showing Location of Study (G.S.N. 1:100,000 series Auchi Sheet 266)

Table 1: Cretaceous Sequence in Southern Nigeria.

\begin{tabular}{lll}
\hline Age & Western Nigeria & Eastern Nigeria \\
\hline Paleocene & Abeokuta Formation & Nsukka Formation \\
Danian & & Ajali Formation \\
Maastrichtian & Mamu Formation & Nkporo Formation \\
& & (Lateral equivalents are Asata Shale, Enugu Shale, Owerri Sandstone) \\
Campanian - Maastrichtian & & Agwu Formation \\
Conancian - Santonian & Basement Complex & Eze - Aku Formation \\
& & (Lateral equivalent Amasiri Sandstone) \\
Turonian & Odukpani Formation \\
Cenomanian & Unnamed Formation (Unconformity) \\
Albian & Abakaliki Shale (Asu River Group) \\
\hline
\end{tabular}

Geological Fieldwork and Sample Collection: Lithologic Description of the Sandstone of Lokoja Formation within the Auchi - Igarra Area: The representative section is about $\mathrm{km} \mathrm{7,} \mathrm{along} \mathrm{Auchi} \mathrm{-}$ Igarra road and alongside River Orle $\mathrm{km} 4$ north of Auchi, The Bawa Hill outcrop along Auchi - Igarra road. It is $20 \mathrm{~m}$ thick and consists mainly of sandstone, sand and clay. These are distinguished or further subdivided on the basis of their physical attributes, which includes colour of sediments, sorting and grain - size.

1. Beginning from the bottom layer of the rock unit, the first $8 \mathrm{~m}$ intervals $(0-8.1 \mathrm{~m})$ consists of medium to coarse grained grits. The sediments are partly indurated - high and studded with quartz pebbles, which are angular to subangular with occasional subrounded outline. Some of the pebbles have diameters ranging between $4.00-4.50 \mathrm{~mm}$, a few horizons are found. The colour varies from white to pinkish brown but purplish variety are also present. It is cross bedded with large scale trough cross bedding. Towards the top, the section is iron - stained.

2 . The second layer $(8.1-9.1 \mathrm{~m}$ thickness $)$ consist of sandy - clay which is about $1 \mathrm{~m}$ thick. It is brownish in colour, fine - medium grained sand and the grains are angular to subangular. Quartz constitute minerals present in this horizon.

3. The third layer $(9.1-13 \mathrm{~m}$ thick $)$ consists of highly consolidated sandstone, coarse grain and containing some quartz pebbles progressively becomes fine grained towards the top. Occasionally, thin bands (about $10 \mathrm{~cm}$ thick) of hard ferruginized sandstone occur. They appear conformable with the bedding, but they are, however, not continuous for a long distance. The grains are subangular - subrounded and moderately sorted. Colour is reddish brown. Both small and large scale trough cross bedding are present at the top. There are sometimes clayey - sand mixture within the layer.

4. The fourth layer $(13-15.9 \mathrm{~m})$ consist predominantly of clay which grades progressively 
upwards to sandy - clay. The clay horizon is typically grayish in colour and massive. The succeeding clay portion is fine to medium grained and highly compacted with clay cementation. The sand grains are subangular to subrounded. The colour varies from light brown to yellowish brown.

5. The fifth layer $(15.9-19.4 \mathrm{~m})$ represent the top most part of the sequence. It's about $3.5 \mathrm{~m}$ thick. It consists of highly ferruginised and indurated sandstone of about $1 \mathrm{~m}$ thick below and succeeded by a portion showing considerable leaching at the top. Grain size ranges from through medium to coarse grain. Sorting is poor and grains are sub-rounded to round.

Grain Size Analysis: 28 samples were mechanically analysed for grain - size distribution. The samples were air - dried and each unconsolidated samples is placed in a large sheet of glazed paper and crushed with finger to disaggregate. Each sample was examined with a hand lens. Fifty grams $(50 \mathrm{~g})$ of each samples were carefully weighed in a chemical balance and poured on by a set of sieve arranged in descending order or mesh diameter from top to bottom and a sieving pan at the base. The top most sieve is covered and these sieves are mounted on an automatic electric shaker for fifteen minutes. At the end, each retained on each sieve or screen was carefully removed and weighed. The weight of each retained fraction is recorded against each sieve and the percentage of each sample was estimated.

Data Analysis: Graphic Mean: This parameter measures the overall size of the sediments which is influenced by source of supply and environment of deposition. Graphic mean proposed by Folk and Ward (1957) is given by:

$$
M_{2}=\frac{\emptyset 16+\emptyset 50+\emptyset 84}{3}
$$

Their classification put this range between fine coarse grained sand. However, the size and unconformity of size and sorting is a measure of the competence and efficiency of the transporting agent (Udden, 1914). Graphic mean values of the analysed samples ranged from minimum $0.27 \varnothing$ to a maximum $2.71 \varnothing$ recorded for a coarse grained sand and a fine grained sand respectively within an average value of about $1.17 \varnothing$. This corresponds to a medium grained sand. However, the medium to coarse grained as revealed by Table 5 predominate, constituting about $82 \%$ and this probably suggests deposition by moderate to fairly high velocity current. Since Graphic Mean values are functions of the velocity of the depositing agent, and thus during the deposition of the sediments the current fluctuated between moderate to fairly high.

Inclusive Standard Deviation: This is the measure of the uniformity or sorting of the sediments i.e the spread (in phi units) of its grain - size distribution. This value as given by Folk and Ward (1957) is:

$$
S D=\frac{\emptyset 84-\emptyset 16+\emptyset 84}{4}+\frac{\emptyset 95-\emptyset 5}{6.6}
$$

The following values are employed for interpretation purposes: Under $0.35 \varnothing=$ Very well sorted; $0.35 \varnothing-$ $0.50 \varnothing=$ Well sorted; $0.50 \varnothing-0.71 \varnothing=$ moderately well sorted; $0.71 \varnothing-1.00 \varnothing=$ moderately sorted; $1.00 \varnothing-$ $2.00 \varnothing=$ poorly sorted; $2.00 \varnothing-4.00 \varnothing=$ Very poorly sorted; Over $4.00 \varnothing=$ extremely poorly sorted

Tables 4 and 5 reveals that most of the samples analysed range from poorly sorted through moderately sorted to moderately well sorted (i.e 7 poorly sorted, 17 moderately sorted, 3 moderately well sorted and 1 well sorted). The Standard Deviation values range from $0.48 \varnothing-1.27 \varnothing$ with an average value of $0.85 \varnothing$, this corresponds to moderately sort. The poor to moderate sorting of the sediments may be suggestive of short distance of transportation and perhaps still nearness to sediment of source. Within the coarse sandy horizon which occurs at the base of the section (sample No. 1 - 19, and $31-46$ ), the sediments are moderately sorted which implies that the drive energy has relatively full effect with less resistance from the encountered bed load. On the other hand, the analysis shows that there is vertical gradation from moderate to poor in the sorting of the sediment, which may be indicative of Cyclic Sedimentation. The rhythmic unit consists of alternating sandstone, sandy - clay and clay.

Inclusive Graphic Skewness: It is a measure of asymmetry of the curve and direction of the tails either to the right or the left. In other words, it indicates any excess of the normal distribution that are present either in finer fraction or coarser fraction (Folk, 1974). Values may be positive or negative and the properties are believed to be important in interpreting environment. Statistically, it is obtained from the equation:

$$
S K=\frac{\emptyset 16+\emptyset 84-2 \emptyset 50}{2(\varnothing 84-\emptyset 16)}+\frac{\emptyset 50+\emptyset 95-2 \emptyset 50}{2(\varnothing 95-\emptyset 5)}
$$

Table 4 reveals that all values are represented with values varying from -0.47 to 1.0 (i.e, strongly coarse skewed to strongly fine skewed). Majority of the samples are strongly fine skewed as reflected by the 
calculated average value of 0.28 . This may be indicative of a fairly coarse material in the tail of the curve deposited under slightly turbulent environment with fairly high energy input (Pettijohn, 1975). It is also observed from these tables that the number of strongly positively skewed sediments is doubled that of negatively skewed sediments. This may also be suggested that the energy of deposition of the former prevailed more than that of the later. The energy of depositing agent is the area, therefore, may be said to be fairly high to moderate most of the time, that is, there is uniform variation in the energy of deposition. The positively skewed sediment is indicative of nearness to the source (Folk and Ward, 1957) and also reflects deposition by rivers or dunes (Friendman, 1961).

Graphic Kurtosis $(K G)$ : This parameter measures the degree of peakedness of the distribution. It also gives ration between sorting in the tail of curve and sorting in the centre position. Hence, indicating the extent of the energy fluctuation of deposition agent with time. It is given by the equation:

$$
K G=\frac{\emptyset 95-\emptyset 5}{2.44(\varnothing 75-\emptyset 25)}
$$

For normal distribution, $\mathrm{KG}$ is fixed at 1.0

The samples have Kurtosis values ranging from between 0.0 to 3.75 (the very Platykurtic to Lepotokurtic) with an average of 0.95 (i.e. Mesokurtic). In terms of abundance, about 18, 7 and 4 samples exhibits Platykurtic, Mesokurtic, Lepotokurtic phenomena respectively (see table 5). The distribution of the kurtosis value with platykurtic sediments predominate over others probably suggests that velocity fluctuation in the area were not restricted within the centre portion of the average velocity for a greater length of time than normal. According to Fork and Ward (1957), extremely high and low Kurtosis values may be said to suggest that part of the sediments achieved sorting elsewhere in a high energy environment, transported essentially with its size unmodified into another environment where it may be fixed with another type of material. The new environment is one of less effective energy of sorting. This in other words implies a fluctuating hydrodynamic condition in the environment of deposition and their effect on sediment distribution.

\section{RESULTS AND DISCUSSION}

Field studies of the outcrop section on the Benin Flank shows that the section is composed dominantly of sandstone with occasional occurrence of sandy clay at intervals. The sandstone and grits which occur mostly at the rock section are medium to coarse grain with pebble occurrence, pinkish colour and iron stained or ferriginous and generally it is moderately to poorly sort. The sandstone is frequently clay supported which make it looks dirty and this is characteristic of submature sandstone.

Also, the sand grains are angular at the base with varieties of colour (ranging from brown, pink, and purplish to whitish grey) and this probably indicates rapid fluctuation between Lacustrine and Deltaic conditions (Picard, 1957).

The presence of large scale Trough - cross beddings is indicative of fluvial environment, clay lense or intercalation in the sandstone beds may represent over bank flood deposit (Potter, 1967). Using the data from the grain size analysis, cumulative curves and probability curves were plotted for the samples. The phi (Ø) diameter value is taken as the abscissas and the percentage value as ordinate.

From the probability curve, the following percentiles were read off from each samples and used in calculating four statistical parameters. Ø5, Ø16, Ø25, $\varnothing 50, \varnothing 75, \varnothing 84$ and $\varnothing 95$. The percentile values are shown in Table 2.

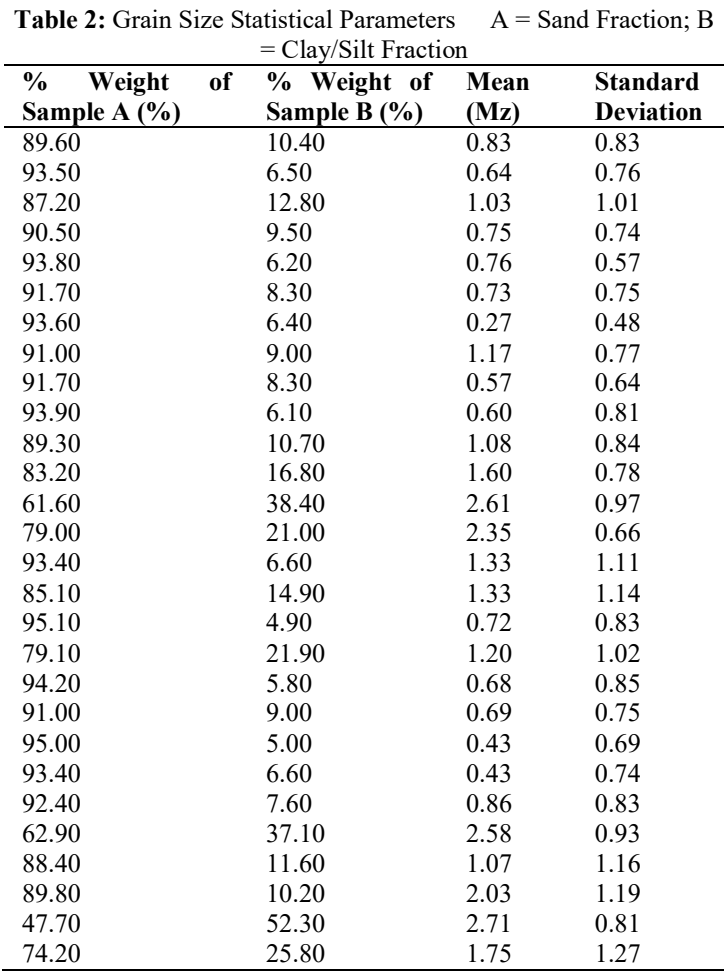


Table 3: Qualitative Description of Statistical Parameters of Analysed Samples

\begin{tabular}{|c|c|c|c|c|c|}
\hline $\mathbf{S} / \mathbf{N}$ & $\begin{array}{l}\text { Sample } \\
\text { No. }\end{array}$ & Graphic Mean & $\begin{array}{l}\text { Inclusive Graphic } \\
\text { Standard Deviation }\end{array}$ & $\begin{array}{l}\text { Inclusive Graphic } \\
\text { Skewness (SK) }\end{array}$ & $\begin{array}{l}\text { Graphic Kurtosis } \\
\text { (KG) }\end{array}$ \\
\hline 1 & 1 & Coarse grained & Moderately sorted & Strongly fine skewed & Platykurtic \\
\hline 2 & 2 & Coarse grained & Moderately sorted & Strongly fine skewed & Platykurtic \\
\hline 3 & 3 & Medium grained & Poorly sorted & Strongly fine skewed & Leptokurtic \\
\hline 4 & 5 & Coarse grained & Moderately sorted & Strongly fine skewed & Platykurtic \\
\hline 5 & 6 & Coarse grained & Moderately well sorted & Strongly fine skewed & Mesokurtic \\
\hline 6 & 7 & Coarse grained & Moderately sorted & Strongly fine skewed & Platykurtic \\
\hline 7 & 9 & Coarse grained & Well sorted & Strongly fine skewed & Extremely leptokurtic \\
\hline 8 & 10 & Medium grained & Moderately sorted & Strongly coarse skewed & Platykurtic \\
\hline 9 & 12 & Coarse grained & Moderately sorted & Strongly fine skewed & Platykurtic \\
\hline 10 & 15 & Coarse grained & Moderately sorted & Strongly fine skewed & Platykurtic \\
\hline 11 & 17 & Medium grained & Moderately sorted & Coarse skewed & Platykurtic \\
\hline 12 & 19 & Medium grained & Moderately sorted & Strongly coarse skewed & Mesokurtic \\
\hline 13 & 21 & Fine grained & Moderately sorted & Coarse skewed & Mesokurtic \\
\hline 14 & 22 & Fine grained & Moderately well sorted & Coarse skewed & Mesokurtic \\
\hline 15 & 23 & Medium grained & Poorly sorted & Nearly symmetrical & Very Platykurtic \\
\hline 16 & 24 & Medium grained & Poorly sorted & Nearly symmetrical & Platykurtic \\
\hline 17 & 25 & Coarse grained & Moderately sorted & Strongly fine skewed & Very Platykurtic \\
\hline 18 & 26 & Medium grained & Poorly sorted & Nearly symmetrical & Platykurtic \\
\hline 19 & 27 & Coarse grained & Moderately sorted & Strongly fine skewed & Platykurtic \\
\hline 20 & 28 & Coarse grained & Moderately sorted & Strongly fine skewed & Very Platykurtic \\
\hline 21 & 29 & Coarse grained & Moderately well sorted & Strongly fine skewed & Leptokurtic \\
\hline 22 & 30 & Coarse grained & Moderately sorted & Strongly fine skewed & Very Leptokurtic \\
\hline 23 & 31 & Coarse grained & Moderately sorted & Strongly fine skewed & Very Platykurtic \\
\hline 24 & 32 & Fine grained & Moderately sorted & Coarse skewed & Mesokurtic \\
\hline 25 & 33 & Medium grained & Poorly sorted & Strongly fine skewed & Platykurtic \\
\hline 26 & 34 & Fine grained & Poorly sorted & Strongly coarse skewed & Mesokurtic \\
\hline 27 & 35 & Fine grained & Moderately sorted & Nearly symmetrical & Mesokurtic \\
\hline 28 & 36 & Medium grained & Very poorly sorted & Coarse skewed & Platykurtic \\
\hline \multicolumn{6}{|c|}{ Table 4: Average Summary } \\
\hline $\mathbf{S} / \mathbf{N}$ & Parameters & & Range of Values & Average Values (Ø) & Verbal Description \\
\hline 1 & Graphic me & & $0.27-2.71$ & 1.17 & Medium grained \\
\hline 2 & Inclusive $\mathrm{Gr}$ & phic Standard Dev & $0.48-1.27$ & 0.85 & Moderately sorted \\
\hline 3 & Inclusive $\mathrm{Gr}$ & phic Skewness & $-0.47-1.00$ & 0.28 & Strongly fine skewed \\
\hline 4 & Graphic Kur & osis & $0.60-3.79$ & 0.95 & Mesokurtic \\
\hline
\end{tabular}

\section{Conclusion:}

Field studies of the sedimentary rock outcrop in the Auchi - Igarra area reveals a distinct rock unit of formational rank. It is composed of partially consolidated sandstone to indurated sandstone with clay support. The statistical analysis shows that the sediments are on the average medium to coarse grained, poorly to moderately sorted, positively fine skewed and mesokurtic. These parameters infer a river deposited sediment, transported mostly by saltation under moderate to fairly high energy condition (Friedman, 1961). The sedimentation was rapid and this gave rise to sediments being poorly to moderately sorted which is indicative of river channel.

\section{REFERENCES}

Adegoke, OS (1969). Eocene Stratigraphy of Southern Nigeria-Memoires du B.R.G.M. No. Pp 69

Adegoke, OS (1978). Ancient Seaways, Sediments and their Recorded History: Inaugural Lecture Series 31. P 43

Adeleye, DR (1975). Nigeria Late Cretaceous Stratigraphy and Paleogeography. American Assoc. Petroleum. Geol. Bull. 59. Pp 2303 - 2313.
Folk, RK (1951). Stages of Textural Maturity in Sedimentary Rocks. J. Sediment. Petrol. 2 (3), Pp $127-130$.

Folk, RL (1974). Petrology of Sedimentary Rock. Hemphille's Austin, Texas, Pp 182.

Friendman, M (1961). Distinction between Dune, Beach and River Sands, from their Textural Characteristics. J. Sediment. Petrol. 31(4), Pp 514-529.

Murat, RC (1972). Stratigraphy and Paleogeography of the Cretaceous and Lower Tertiary in Southern Nigeria. In Dessauvagie, T.F.J. and Whiteman, A.J. eds. Afr. Geo. Pp $251-266$

Pettijohn, PJ (1975). Sedimentary Rock. Harper \& Row, N.Y., Pp 628 ( $3^{\text {rd }}$ ed.)

Picard, MD (1957). Criteria used for Distinguishing Lacustrine and Fluvial Sediments in the Tertiary Beds of Uinta Basin, Utah. J. Sediment. Petrol. 27: Pp $372-377$. 